\title{
O Brasil e a Grande Estratégia dos EUA: aspectos históricos conjunturais
}

\section{Brazil and the Great Strategy of the USA: historical and conjunctural analysis}

Rev. Bras. Est. Def. v. 6, nº 1, jan./jun. 2019, p. $217-240$

DOI: $10.26792 /$ RBED.v6n1.2019.75080

ISSN 2358-3932

\section{BRUNA COELHO JAEGER PEDRO VINÍCIUS BRITES}

\section{INTRODUÇÃO}

Este trabalho tem como objetivo principal analisar a evolução da Grande Estratégia dos Estados Unidos e a relevância que o Brasil assume para os EUA ao longo do período analisado. Mais especificamente, procura vincular as oscilações nas relações Brasil-EUA e as variações no contexto geopolítico da América do Sul sob a perspectiva brasileira. Assim, procura-se depreender os indicadores que permitem avaliar se o lugar do Brasil na Grande Estratégia dos EUA varia conforme as mudanças nos objetivos estratégicos dos EUA, ou se vinculam-se principalmente às próprias mudanças do perfil de inserção internacional do Brasil.

$\mathrm{O}$ conceito de Grande Estratégia adotado nesta pesquisa refere-se ao alinhamento entre os objetivos políticos de longo prazo de um país e as capacidades materiais efetivas para colocar esse projeto em prática (Porter 2013; Montgomery 2014). As transformações na Grande Estratégia dos EUA implicam em mudanças na ordem internacional e no equilíbrio geopolítico global. No governo Trump, os EUA reafirmaram o Leste Asiático e a Europa como regiões prioritárias, espaços geoestratégicos das disputas

\footnotetext{
Bruna Coelho Jaeger - Professora de Relações Internacionais no Centro Universitário LaSalle do Rio de Janeiro (UniLaSalle/RJ). Professora substituta no Instituto de Relações Internacionais e Defesa da Universidade Federal do Rio de Janeiro (IRID/UFRJ). Doutoranda em Economia Política Internacional na Universidade Federal do Rio de Janeiro (PEPI/UFRJ). Bolsista CAPES. Mestra em Estudos Estratégicos Internacionais pela Universidade Federal do Rio Grande do Sul (PPGEEI/ UFRGS) e Bacharela em Relações Internacionais (UFRGS).

Pedro Vinícius Brites - Doutor em Estudos Estratégicos Internacionais (UFRGS) e ProfessorCooordenador do curso de Relações Internacionais no Centro Universitário Ritter dos Reis (UniRitter). Mestre em Estudos Estratégicos Internacionais pela Universidade Federal do Rio Grande do Sul (PPGEEI/UFRGS) e Bacharel em Relações Internacionais (UFRGS).
} 
com China e Rússia, respectivamente. A Estratégia de Segurança Nacional (2017) deixa bem clara essa postura:

China e Rússia desafiam o poder, a influência, e interesses americanos, erodindo a segurança e a prosperidade americana. Eles estão determinados a tornar as economias menos livres e menos justas, a ampliar suas capacidades militares e a controlar informações e dados para reprimir suas sociedades e expandir sua influência. [...] Essas competições exigem que os Estados Unidos repensem as políticas das duas últimas décadas - políticas baseadas na premissa de que o engajamento com os rivais e sua inclusão nas instituições internacionais e no comércio global os transformaria em atores benignos e parceiros confiáveis. Em grande medida, essa premissa revelou-se falsa (U.S. 2017, 2-3). ${ }^{1}$

A América Latina, nesse contexto, não se configura em espaço estratégico, o que limita a capacidade do Brasil em colocar-se como ator relevante para a política externa dos EUA. Na National Security Strategy (NSS) de 2017, a América Latina é citada apenas uma vez, e o Brasil sequer é mencionado. A citação à América Latina no documento ocorre dentro do pilar de avanço da influência americana, no âmbito da estratégia nos contextos regionais, e nem de modo autônomo está inserida dentro do item voltado ao hemisfério ocidental. Além disso, o foco na realpolitik esvazia as instituições internacionais, arenas prioritárias da atuação do Brasil historicamente. Assim, este estudo apresenta a hipótese de que a posição do Brasil na agenda externa dos EUA varia conforme a política externa brasileira, que, quanto mais alinhada a Washington, menos relevante o Brasil torna-se para os EUA. Tendo isso em vista, e o cenário de descarte completo da prioridade geoestratégica da América do Sul apresentado nos últimos documentos estratégicos, conclui-se que o Brasil não tem relevância nessa nova fase da Grande Estratégia dos Estados Unidos, ${ }^{2}$ o que, em grande medida, é resultado do retraimento da política externa brasileira. Esse cenário vincula-se a dois processos convergentes. O primeiro processo é o abandono por parte do Brasil - e por razões meramente ideológicas — de seu projeto de liderança regional e de projeção internacional, o que implicou em uma auto-contenção. Somado a isso, o retraimento do Brasil da sua busca por configurar-se como mediador internacional no âmbito global, fato que, somado à posição geopolítica do Brasil, distante das disputas com as potências desafiantes elencadas pelos EUA, coloca o país em um plano secundário na agenda externa do país. O segundo processo é a retomada da realpolitik por parte de Washington e o foco na busca da primazia nas disputas estratégicas com China e Rússia. 
Esta pesquisa, portanto, procura aliar os esforços analíticos sobre a estruturação das relações entre Brasília e Washington ao entendimento dos efeitos das rupturas e alterações na ordem mundial desde a década de 1970 (1969-2008). Grosso modo, essas rupturas podem ser agrupadas em quatro fases: (i) a Doutrina Nixon (1969), a Guerra do Vietnã (1955-1975), o abandono do padrão-ouro (1971) e a primeira crise do petróleo (1973); (ii) segunda crise do petróleo (1979), crise da dívida externa nos países do terceiro mundo (anos 1980); e guerras (ou instabilidade política e social) nos Estados-Pino (Irã, Afeganistão, Vietnã, Polônia) - operacionalizando-se o conceito de Brzezinski (1986); (iii) a queda da URSS (1991), a globalização e o Consenso de Washington (1989); e (iv) crises do neoliberalismo, Guerra ao Terror, crise financeira (2007-8). A soma dessas rupturas representou uma inflexão na evolução do capitalismo (Hobsbawm 2010) e o início do declínio do arranjo político, econômico e social estabelecido no final da II Guerra Mundial. Portanto, esse conjunto de transformações na ordem internacional, que corroboram para a hipótese de recomposição hegemônica, impactaram diretamente sobre a atuação do Brasil no plano regional.

A fim de cumprir com seus objetivos, este trabalho combina a análise histórica com a análise da Grande Estratégia dos EUA (especialmente através da análise de documentos oficiais). Assim, está dividido em duas seções. A primeira realiza uma análise da formação e estruturação das relações Brasil-EUA, abrangendo desde a doutrina Monroe até o final da Guerra Fria. A seguir, a segunda seção realiza uma análise das relações bilaterais no período posterior à Guerra Fria, e termina conjugando os esforços analíticos das seções anteriores, voltados a uma análise de conjuntura, na qual investiga-se os impactos para o Brasil a partir do endurecimento da política externa de segurança dos EUA no governo Trump. Por fim, cabe destacar que esta pesquisa realiza uma abordagem não necessariamente linear, mas de eventos que contribuem para a compreensão das mudanças que são analisadas na atualidade. Ou seja, busca-se discutir como a posição brasileira em relação aos EUA oscilou ao longo do período analisado, e se essas variações são impulsionadas pelas mudanças na Grande Estratégia ou atendem às mudanças no contexto brasileiro.

\section{A EVOLUÇÃO DA GRANDE ESTRATÉGIA DOS EUA E AS RELAÇÕES COM BRASIL: DO SÉCULO XIX ATÉ A GUERRA FRIA}

O objetivo desta seção é realizar uma análise histórica da relação Estados Unidos-Brasil. Busca-se, portanto, discutir como o Brasil reagiu e foi afetado pelos principais redirecionamentos da Grande Estratégia dos EUA ao longo da história. 
A fim de analisar a relação bilateral, deve-se ter em consideração a forma como os EUA distinguem o Brasil em sua pauta estratégica. Especialmente desde o seu período expansionista, a política externa e de segurança dos EUA tende a perceber a América Latina como um conjunto homogêneo, cujo padrão de engajamento e contenção se dá muitas vezes sem diferenciar as especificidades de cada país. Em sua maioria, isso é reflexo de não representarem ameaça ou oposição dura à potência hegemônica, buscando assim angariarem maiores benefícios com o alinhamento. Ainda que o Brasil tenha como padrão de conduta de sua política externa a busca por autonomia, é notável que em poucos momentos de sua história representou uma oposição ao alinhamento com a potência hegemônica. Portanto, o país não se consolidou como uma pauta relevante na estratégia de contenção e engajamento dos EUA, e sim como um parceiro nas políticas de estabilização e manutenção da esfera de influência norte-americana. Como aponta Pecequilo (2015, 105): "Se o Brasil, por suas escolhas, já delimita marginalmente sua atuação, não há necessidade de os Estados Unidos oferecerem concessões ao país, engajando-o. Ou seja, não há o que conter, e o país some do radar de prioridades como Estado pivô, diferente da China e da Índia”. No entanto, para compreender como a Grande Estratégia dos EUA influencia na Política Externa Brasileira, é essencial retomarmos as origens das políticas hemisféricas dos EUA. A preocupação da política externa norte-americana em relação ao hemisfério data do início do século XIX.

Cabe destacar que, embora a Grande Estratégia dos EUA tenha oscilado ao longo da história, majoritariamente ela atende a dois objetivos principais: a segurança estratégica e a segurança energética. Fiori (2017) define assim os dois objetivos:

a) o objetivo da "segurança estratégica" dos EUA, envolvendo a prevenção ou eliminação de toda e qualquer ameaça aos seus interesses nacionais e militares, em qualquer ponto do mundo; incluindo o controle naval e aeroespacial de todos os "fluxos" relevantes para o exercício desta supremacia estratégica global.

b) com ênfase particular na "segurança energética" das forças militares e econômicas dos EUA e de seus principais aliados, com o controle do acesso às principais fontes de energia, mantendo seu direito ao bloqueio instantâneo, - em caso de necessidade ou beligerância do acesso a elas, por parte dos seus concorrentes ou inimigos (Fiori $2017, \mathrm{~s} / \mathrm{p}$.).

A Grande Estratégia que resulta do equilíbrio dos objetivos e das duas perspectivas foi-se moldando desde a independência do país no final do 
século XVIII, consolidando-se ao longo do século XIX e culminando na conquista definitiva da condição hegemônica após a II Guerra Mundial. O processo de consolidação territorial, com a conquista do México e ingerência sobre a América Central, bem como a expansão em direção ao Pacífico, refletem esse processo de formação imperial que caracteriza a primeira fase da Grande Estratégia dos EUA.

A Doutrina Monroe tem seus princípios éticos formadores herdados da Declaração de Independência de 1776, e foi lançada em 1823 através do discurso do Presidente James Monroe. Enaltece os valores de autogoverno, liberdade e liderança pelo exemplo. No contexto do final do século XIX, no qual a conformação territorial das fronteiras continentais do país encontrava-se estável e mais bem definida, os Estados Unidos podiam enfim inserir-se na corrida imperialista internacional, ainda que com um discurso diferente das então potências tradicionais. Nesse sentido, de acordo com Pecequilo (2011, 79), o expansionismo americano teria provocado uma transformação paradigmática na política externa do país, justificando-se em três níveis: intelectual, econômico e estratégico. O rechaço à interferência europeia no continente americano por parte da intelectualidade estadunidense encontrava apelo nos preceitos da Doutrina Monroe. Em termos econômicos, a necessidade de assegurar a zona de influência nas Américas era imperativa no contexto da Segunda Revolução Industrial e da decorrente corrida imperialista por acesso a territórios, rotas e matérias primas, dando origem também à política de portas abertas. "Os Estados Unidos deveriam assumir, no exterior, um lugar e um papel compatíveis com seus recursos de poder, prevenindo-se de antemão das ameaças de adversários potenciais" (Pecequilo 2011, 81). Assim, a exclusão de ameaças externas e a garantia de estabilidade regional são aspectos que perduram desde então dentre as preocupações da política externa dos EUA para a América Latina, associando a segurança doméstica com a de outros países.

Ao final do século XIX, o Brasil transita da esfera de influência britânica para a americana, acompanhando os próprios rumos da transição hegemônica. Se a política imperial era reativa ao estabelecimento de qualquer forma de protetorado dos EUA sobre as Américas, a instauração da República concomitante à I Conferência Internacional Americana (18891890) inaugurou uma nova fase da diplomacia brasileira, imbuindo-a do "espírito americano" na Política Externa Brasileira (PEB). Ademais, o contexto marca o desejo dos EUA em aumentar sua influência sobre o Brasil, face à posição estratégica do país e à oposição representada pela Argentina. Nesse contexto, o Brasil era um importante aliado dos EUA como estabilizador regional. Dessa forma, o início do século XX combina dois processos concomitantes e definidores da relação bilateral: por um lado, o Corolário 
Roosevelt à Doutrina Monroe (1904-1909) e, de outro, a fase de Barão de Rio Branco à frente da diplomacia brasileira. A íntima aproximação do Brasil republicano com os EUA atendia primordialmente a interesses oligárquicos, que empreenderam diversos tratados preferenciais de comércio - a maioria ligados ao café. Entretanto, essa aproximação não representava um alinhamento automático, e sim a visão realista e pragmática de Rio Branco quanto à ascensão dos EUA no Sistema Internacional e o lugar da América do Sul no subsistema americano de influência (Cervo and Bueno 2011). Assim, o apoio do Brasil ao Corolário Roosevelt atendia aos objetivos da PEB de resguardar a América do Sul da ingerência europeia. O uso da força para garantir a estabilidade da região marca as origens da diplomacia do dólar e da transição hegemônica, visto que os EUA tomavam para si em definitivo o papel de assegurar a responsabilidade fiscal dos países latino-americanos. O Brasil, na conjuntura de consolidação fronteiriça, não desaprovava o papel de polícia dos EUA na região. Em outras palavras: a Doutrina Monroe era percebida por Rio Branco com um caráter defensivo, visto que a alternativa europeia era descartada face às ameaças que representava aos interesses lindeiros do Brasil.

A partir de 1929, com a quebra da bolsa de Nova Iorque e a Grande Depressão que acompanha esse fenômeno, inicia-se um processo de redirecionamento decisivo na relação EUA-Brasil, tanto por meio das políticas hemisféricas como da PEB e da construção da hegemonia americana de projeção global. O período marcado pelos governos de Franklin D. Roosevelt (1933-1945) e de Getúlio Vargas (1930-1945) inaugura uma nova fase na estratégia geopolítica dos EUA em relação ao Brasil, de engajamento e contenção. Se o lugar de um país na Grande Estratégia americana define-se pela sua posição geoestratégica e pelo grau de autonomia observada em sua política externa e de segurança, o Brasil alcança condição de grande relevância nesse contexto - isto é, a percepção dos EUA acerca de uma potência relevante posiciona o Brasil na estratégia de engajamento, por meio de concessões políticas e econômicas, com a finalidade de conter e de garantir a aliança preferencial.

No período entreguerras, o debate internacionalismo versus isolacionismo ganha força dentro da sociedade americana e entre os tomadores de decisão. Ainda assim, o país manteve os objetivos de liderança regional, apesar da recessão econômica. Há uma mudança de tática nessas políticas, contudo, visto que as intervenções estabelecidas no Corolário Roosevelt começaram a ser percebidas como custosas e contraproducentes. Desse modo, a construção da hegemonia, especialmente na região, passa a associar-se à cooperação e à inclusão, pautando-se num discurso que mesclava idealismo com materialismo (Brzezinski 2012) - o que pode ser visto co- 
mo um novo padrão de conduta consolidado nesse período e que perdura em muitas fases da Grande Estratégia americana.

A busca pela manutenção de Estados clientes e pelo afastamento de inimigos externos encontra na política externa de Vargas um obstáculo. Assim, o lançamento da Política da Boa Vizinhança representou uma grande reorientação, uma vez que basearia a política hemisférica em processos de cooperação e consulta, objetivando especialmente o incremento das relações comerciais com a região. A consolidação da esfera de influência deveria passar por outras formas, a partir da retirada das tropas remanescentes na região e o abandono das intervenções. A "pan-americanização da Doutrina Monroe” (Atkins 1989), no entanto, não deixaria de lado as preocupações centrais de estabilização do entorno regional e de afastamento das demais potências extraterritoriais. Dessa forma, segundo Pecequilo (2011), acabou sendo mais uma mudança tática do que estratégica, posto que os preceitos da Doutrina Monroe se mantiveram intactos, não havendo tantas medidas concretas para garantir a efetivação da cooperação e o abandono das intervenções.

A diplomacia da Era Vargas buscou abranger novas formas de cooperação e barganha visando ao interesse nacional. O reforço do pragmatismo como padrão de conduta da $\mathrm{PEB}$ se juntou à posição de neutralidade que se manteve até 1942, voltando-se aos objetivos do desenvolvimento nacional. Entretanto, apesar do aumento da participação alemã no comércio brasileiro e sul-americano entre 1934 e 1938, o Brasil acaba apostando definitivamente nos EUA ao final da década, principalmente como decorrência da missão diplomática de Osvaldo Aranha àquele país em 1939. Desse modo, o recuo da equidistância pragmática decorre da leitura dos formuladores da PEB de que faltava à Alemanha as condições efetivas para satisfazer às necessidades do Brasil (Cervo and Bueno 2011). Além disso, tendo em vista que a história da $\mathrm{PEB}$ é mais marcada por continuidades do que por mudanças, o reconhecimento da liderança americana se somou à já consolidada tradição de cordialidade e cooperação no relacionamento bilateral.

A preocupação central dos EUA na região era, portanto, eliminar as influências do Eixo, principalmente no Brasil e na Argentina (Moniz Bandeira 2010). A Política da Boa Vizinhança servia a esse propósito, com o objetivo de engajar os aliados regionais ao pan-americanismo. Ademais, os EUA tinham interesses concretos na posição geopolítica do nordeste brasileiro e nos minerais estratégicos do país. O Brasil, por sua vez, buscava na política externa para o desenvolvimento a modernização das suas Forças Armadas, bem como maior prestígio internacional. A estratégia utilizada inicialmente pela diplomacia brasileira foi a de neutralidade, o que acabou sendo contida através das políticas de engajamento empreen- 
didas pelos EUA, principalmente oferecendo concessões ao setor militar do país (a princípio mais simpático ao Eixo) e ao projeto siderúrgico de Vargas.

Com o final da II Guerra Mundial, inicia-se um processo de grande deterioração nas relações hemisféricas e de negligência das políticas norte-americanas para a América Latina. Após a vitória na II Guerra Mundial, os EUA buscaram consolidar uma Grande Estratégia de engajamento profundo (deep engagement) assentada em dois pilares: de um lado, na consolidação da defesa avançada e na proteção aos seus aliados; de outro, na construção de uma hegemonia liberal respaldada por um arcabouço de instituições internacionais. Em termos geopolíticos, a prioridade era a defesa da Europa Ocidental, o que reflete a vitória política da ala atlântica sobre a ala que defendia a priorização da Ásia. Mais do que isso, com o advento das armas nucleares, os EUA estabeleciam uma primazia ímpar na sua história. Pode-se dizer que, nesse sentido, as armas nucleares eram as fiadoras dessa nova ordem internacional e estavam no cerne da Grande Estratégia dos EUA. Entretanto, à medida que URSS, Reino Unido, França e, pouco tempo depois, a China tornam-se países nuclearmente armados, a condição de primazia erodiu. Assim, o equilíbrio de poder entre URSS e EUA durante a Guerra Fria residiu nas guerras locais em regiões periféricas do globo. A Destruição Mútua Assegurada, ou equilíbrio estratégico, determinou que o poder convencional se mantivesse como fundamental para estruturação da ordem internacional. O teatro principal das disputas entre EUA e URSS continuava a ser a Europa Ocidental, embora o sul e sudeste asiático, o Oriente Médio e o continente africano fossem palco colateral das disputas entre as duas superpotências (Martins 2008).

Nesse contexto, quanto ao Brasil, há uma retomada das políticas de interferência, ainda que muitas vezes indiretas. Os EUA haviam finalmente alcançado o status hegemônico, passando a adotar de forma definitiva a orientação e a vocação global em detrimento do foco na esfera de influência regional. É o que Peter Smith (1996) chama de hegemony by default, ou seja, mantêm-se os parâmetros do relacionamento continental, mas a movimentação da Grande Estratégia é focada na Eurásia. O Brasil, nesse contexto, não alcançou os ganhos que esperava com o alinhamento. Ademais, a vitória do internacionalismo na inserção externa dos EUA estabelece uma hegemonia em escala mundial, que se fundamenta através de mecanismos e organizações internacionais.

Tradicionalmente, a América Latina está mais relacionada às preocupações domésticas (ou intermésticas) dos EUA, visto que o entorno regional estável é imperativo à segurança imediata do país (Pecequilo 2015). Dessa forma, os períodos de maior isolamento internacional dos EUA coincidem 
com uma maior atenção ao sistema americano. Portanto, a partir da Guerra Fria, em um primeiro momento, a região não tinha relevância na estratégia estadunidense de contenção por três razões principais: estando os países mais subordinados, houve naturalmente um maior descaso dos EUA, bem como maior interferência no lugar da estratégia de engajamento; além disso, a prevenção da instabilidade e a exclusão das ameaças extracontinentais não pareciam estar em jogo. Até mesmo o estabelecimento do TIAR (1947) e da OEA (1948) não foi efetivo em manter o bom nível do relacionamento atingido no período Roosevelt.

A América Latina só alcança um lugar de destaque na estratégia dos EUA quando a influência soviética na região torna-se uma ameaça definitiva. A partir da Revolução Cubana (1959), há concomitantemente um processo de crescimento dos movimentos de esquerda em países como Argentina, Brasil e Chile, o que não podia ser aceito, mesmo que a maior parte se desse através de processos democráticos (Cervo and Rapoport 2015). Nicholas Spykman (1942) já havia alertado de que na "zona equidistante da América do Sul”, com Estados mais desenvolvidos, poderia surgir uma ameaça à liderança regional dos EUA, o que deveria ser respondido com medidas de força (Mello 1999). Por conseguinte, há um fenômeno de destituição e deslegitimação de governos eleitos de forma democrática em troca de regimes ditatoriais e autoritários, ainda que de forma indireta. Em outras palavras, o afastamento da URSS era mais importante do que a promoção da experiência republicana e democrática. A adesão ao sistema interamericano não dependia do perfil dos regimes políticos, e sim da subordinação ao centro hegemônico. Pela análise de Brzezinski (1986), as estratégias adotadas na Guerra Fria por EUA e URSS priorizavam muito mais o aspecto geopolítico do que o ideológico.

Taticamente, dentro da lógica da contenção, isso significou uma alteração das medidas que vinham sendo direcionadas à região, antes restritas ao estabelecimento do sistema interamericano e à assinatura de tratados bilaterais, passando-se a uma ação mais efetiva (Pecequilo 2011, 223).

A diplomacia brasileira, que no contexto da Operação Pan-Americana (1958) adotava um tom reivindicatório nas suas relações com os EUA, insistindo no aumento dos fluxos de ajuda para o desenvolvimento, não alcança os objetivos esperados devido à conjuntura de perda de barganha no relacionamento bilateral. No entanto, a partir da Política Externa Independente (1961-1964) e das demonstrações de antiamericanismo na sociedade brasileira, os EUA aumentam as atenções sobre o país. A Aliança para o Progresso (ALPRO) é lançada como reação a esses acontecimentos, 
a partir de uma leitura de que o subdesenvolvimento e a pobreza seriam atraentes às ideias comunistas e gerariam instabilidades na região. Nesse sentido, representava mais uma interpretação da Doutrina Monroe, tal como a Política da Boa Vizinhança havia sido. Mas igualmente não foi efetiva em findar com as políticas de interferência e unilateralismo dos EUA, sendo, portanto, um episódio breve das relações hemisféricas.

Com a ascensão de Nixon e Kissinger (1969-1974), retoma-se o padrão de relativa negligência. Os EUA alteraram as prioridades geoestratégicas,$~^{3}$ embora o objetivo prioritário da Grande Estratégia ainda fosse a contenção da URSS. Nesse sentido, a triangulação estratégica com a China, estabelecida a partir de 1971 e articulada por Henry Kissinger, altera o equilíbrio de poder entre as superpotências. Além disso, nessa fase, os EUA adotam um desengajamento relativo de algumas regiões do globo. Desse modo, Washington adotava uma postura na qual defendiam que seus aliados deveriam exercer um papel mais atuante em termos de segurança regional. Em outros termos, os EUA abdicaram parcialmente do papel de fiador securitário, mantendo seus aliados sob seu guarda-chuva nuclear, mas transferindo parte dos custos e responsabilidades.

Em termos geopolíticos, a Ásia passa a assumir posição prioritária para os EUA. Apesar do governo de Jimmy Carter (1977-1981) ter revisto, em grande medida, políticas de Nixon, este manteve a prioridade geoestratégica centrada na massa euroasiática. Com a crise da détente, os EUA adotam a estratégia de cercamento do heartland através do rimland, pressionando o entorno estratégico soviético (Mello 1999). Embora o início dos anos 1970 tenha sinalizado o enfraquecimento dos EUA, especialmente em virtude da Guerra do Vietnã, ao final da década os EUA desenvolveram uma série de novos armamentos e equipamentos não nucleares que viabilizaram essa estratégia de pressão hegemônica sobre a URSS. O desenvolvimento, por exemplo, das munições guiadas de precisão (Mearsheimer 1982) determinaram a relativização da superioridade de forças convencionais que a URSS teria sobre os EUA em eventual confronto na Europa Ocidental e permitiram que os EUA ampliassem a pressão geopolítica no entorno soviético. Nesse contexto, os EUA passaram a buscar a primazia e a desestruturação do equilíbrio nuclear que preponderou durante a Guerra Fria.

Nesse contexto, a América Latina não tinha lugar na Grande Estratégia da détente, a qual priorizava as grandes potências. Para o Brasil, o ambiente internacional estava mais propício para a sua atuação externa, devido ao relaxamento da Guerra Fria e do combate ao comunismo (Vizentini 2004). Inclusive, desde a gestão Geisel, o pragmatismo tornou-se uma característica da PEB, o que Letícia Pinheiro (2000) aponta ser o traço mais fundamental da condução externa do país, ao lado do realismo. Para 
Sennes (2003), de Geisel a Sarney esse pragmatismo da PEB foi baseado em uma perspectiva terceiro-mundista, ainda que seletiva e limitada. Essa atuação, especialmente nos organismos multilaterais, teria sido a "segunda melhor opção" estratégica para o país, visto que os recursos de poder eram limitados para agir de forma unilateral e alcançar os objetivos de projeção como potência (Sennes 2003). Contudo, Carter (1977-1981) inicia o processo de reengajamento a partir de uma nova agenda em relação à região, priorizando os temas relativos aos direitos humanos, drogas, imigração e não-proliferação nuclear. Essa agenda respondia às demandas dos EUA e não dos países latino-americanos, a partir de uma instrumentalização da pauta dos direitos humanos como nova forma de intervenção. No governo Reagan (1981-1989), há uma retomada do sistema americano como teatro estratégico preferencial, objetivando recuperar a influência perdida na região. Ancorando-se no redirecionamento da Grande Estratégia da contenção para a busca da primazia, ${ }^{4}$ em relação à América Latina empreende-se uma revitalização da Doutrina Monroe, principalmente por meio de acordos militares. Além disso, a potência hegemônica passa a pressionar os vizinhos do sul por profundas reformas econômicas, com incentivo à lógica do mercado e da livre iniciativa. Foi, portanto, o enquadramento definitivo de países como o Brasil, com objetivo de bloquear o desenvolvimentismo pragmático, o qual estava assentado na estratégia de diversificação de parcerias. ${ }^{5}$

\section{AS RELAÇÕES BRASIL-EUA NO CONTEXTO PÓS-GUERRA FRIA}

No período pós-Guerra Fria, as relações entre Brasil e EUA foram permeadas pela terceira e quarta fases da ruptura da ordem internacional mencionadas anteriormente. A terceira, marcada pelo avanço profundo do neoliberalismo no mundo, e sensivelmente na América Latina, afetou profundamente o modelo de desenvolvimento, o perfil do Estado na região e as estratégias de inserção internacional dos países sul-americanos. Além dos impactos sociais e econômicos, observa-se efeito direto sobre a geopolítica regional, à medida que adesão ao neoliberalismo leva ao sucateamento das indústrias de defesa da região, à destruição da indústria naval no Brasil, e abre o mercado de energia e mineração às grandes corporações internacionais. A quarta fase, por sua vez, marcada pela crise do neoliberalismo, abriu espaço para o estabelecimento de dinâmicas regionais mais autônomas em relação às dinâmicas sistêmicas. Ou seja, permitiu a reconstrução de projetos nacionais modernizantes e voltados à retomada da indústria de defesa, ao controle dos recursos naturais na região e à construção de mecanismos mais complexos de integração regional sem a presença dos EUA. 
Com o fim da Guerra Fria, e a perspectiva da unipolaridade de Washington, o alinhamento apresenta-se como alternativa principal a ser adotada pelo Brasil. Embora não tenha havido uma definição quanto à Grande Estratégia dos EUA, a busca pela primazia condicionou o enquadramento aos regimes internacionais, ainda que o alinhamento tenha sido uma escolha racional feita pelos então tomadores de decisão. O período de unilateralismo inconteste dos EUA somente pode ser observado no imediato pós-Guerra Fria, não perdurando ao longo de toda a década de 1990. Ou seja, a opção pelo alinhamento foi feita sem uma leitura das potencialidades que o Brasil teria no novo ordenamento internacional que estava se formando. O neoliberalismo é implementado no Brasil e em quase todos os países da América Latina mais do que em qualquer outra região do globo, sendo as diretrizes do Consenso de Washington absorvidas de forma bastante ortodoxa. Ainda que se mantivesse à margem da Grande Estratégia norte-americana, a América Latina passa a ser vista como uma área pacífica e estável, com muitas oportunidades subaproveitadas para uma agenda liberal. A NSS (1991) enfatiza a necessidade de, diante desse novo contexto de redemocratização na América Latina, Washington passar a defender a importância das reformas de mercado como elemento estratégico. Nesse sentido, o apoio à "transição democrática e econômica" seria elemento essencial para a governança da região, especialmente através do estabelecimento de uma área de livre-comércio na região. Destacase ainda a ênfase dada ao combate às drogas como elemento central na estratégia de segurança para a região (NSS 1991). Os EUA precisavam recuperar a influência regional perdida e, portanto, passam a apostar em uma estratégia de menos interferência e mais estímulo a mecanismos multilaterais e instituições regionais.

Ao contrário das iniciativas do passado, as dos anos 1990 não tinham como objetivo principal combater a influência de potências extracontinentais, e sim readequar a política externa dos EUA - no entanto, sem relativizar sua hegemonia no hemisfério ou renunciar à sua posição. Deu-se como mais uma readaptação da Doutrina Monroe, mantendo as preocupações tradicionais de área de influência natural e de construção da ordem. Conforme analisa Huntington (1997), em uma avaliação da nova ordem internacional, os EUA precisavam consolidar seu próprio bloco regional como reação ao declínio relativo no sistema. A Iniciativa para as Américas (1990), o Nafta (1991) e a ALCA (1994) são os principais esforços da política externa dos EUA nesse sentido. Apesar de inaugurarem a perspectiva do regionalismo aberto, mantiveram-se os vícios de não levar em conta as especificidades da região e o próprio peso da hegemonia, o que estabelece uma relação demasiadamente assimétrica em qualquer arranjo regional. $\mathrm{O}$ 
Brasil é resistente a essas iniciativas, majoritariamente por medo de perder capacidade de barganha no sistema e ter sua autonomia cerceada pela subordinação às políticas norte-americanas. Ademais, sobressaem-se nas relações hemisféricas os problemas de segurança domésticos dos EUA, que posicionam as agendas do crime transnacional e da imigração ilegal em uma estratégia de combate na fonte e não por meio de políticas públicas internas.

Nos anos 2000, a Grande Estratégia dos EUA se mantém indefinida e errática, o que abre espaço para potências emergentes como o Brasil buscarem maior afirmação regional e global. O caráter errático deve-se às alterações de prioridade e à própria evolução das capacidades militares do país ao longo do século XXI. Em um sentido, Washington priorizou, por exemplo, a contenção das ameaças terroristas no contexto do Oriente Médio, mas, em outro momento, passa a priorizar a busca pela primazia e o subsequente balanceamento de Rússia e China. Essas oscilações derivam também do fato de que os EUA ora optam, do ponto de vista de capacidades materiais, pela adesão a conceitos operacionais voltados ao apoio aos aliados regionais (Offshore Balance), ${ }^{6}$ ora pela adoção do Air Sea Battle (inserido no contex to Joint Operational Access Concept - JOAC), voltado ao ataque em profundidade e preventivo. A NSS (2002), lançada no contexto pós-1 1 de setembro, diminuiu o espaço dado à América Latina. $\mathrm{O}$ foco recaiu sobre a estratégia global de combate ao terrorismo e as políticas de não-proliferação. A América Latina só é mencionada no que tange ao combate às drogas, com a ênfase dada sobre a situação na Colômbia.

Diante desse contexto, a diplomacia brasileira não precisava mais ser tão reativa aos EUA, que deixa de ser uma condicionante da PEB. Em outros termos, a redução da pressão hegemônica dos EUA sobre a região abre espaço para a ampliação de interações regionais autônomas e para uma maior capacidade de agência por parte do Brasil. Com isso, abre-se caminho para que o Brasil consiga edificar iniciativas de ampliação da construção regional que não tivessem os EUA como principal mediador. Inclusive, a reativação da Quarta Frota em 2008 e o aumento dos investimentos no Comando do Sul (USSOUTHCOM) são uma reação ao avanço da construção de liderança regional do Brasil às influências do governo chavista e às descobertas de petróleo e gás na camada pré-sal, cujos investimentos brasileiros em defesa no Atlântico Sul disputam espaço com EUA e Grã-Bretanha em sua rota estratégica (o projeto de construção de um submarino nuclear, bem como o estabelecimento do marco regulatório do pré-sal são exemplos concretos desse processo).

Especialmente, os EUA passaram a buscar formas de contenção ao soft balancing sul-americano, que, apesar de não ser confrontacionista, visava 
ao fortalecimento autônomo, renovação e busca por novas parcerias, e aumento do espaço de manobra e influência nos arranjos e instituições multilaterais. A ofensiva do governo Obama (2009-2017), apesar de focada na Eurásia e em arranjos como o TPP, ocorre muito no sentido de neutralizar o avanço dos emergentes. ${ }^{8}$ A National Security Strategy $(2010)^{9}$ tinha como objetivo principal a renovação da liderança dos Estados Unidos no mundo. O novo momento do Brasil e a crescente liderança do país na região são mencionados no documento, o que evidencia uma ampliação do espaço que o país ocupa na estratégia dos EUA.

O revigoramento do Mercosul, a criação da Unasul (2008) e a atuação dos BRICS são representativos desse processo de grande intensidade da $\mathrm{PEB}$, que visava a igualar-se ao comportamento das grandes potências (Cervo 2008). Além disso, o aumento da presença chinesa na América Latina e as parcerias com o Brasil (com destaque para a construção de grandes obras de infraestrutura e a participação massiva no Leilão de Libra) impelem os EUA a conterem a atuação geopolítica sino-brasileira. Igualmente importantes são os efeitos da Política Nacional de Defesa lançada em 2005, que altera a percepção de ameaça do Brasil, ampliando-a quanto à possibilidade de ataque por uma potência estrangeira. Em 2005, com o estabelecimento do Diálogo Estratégico Brasil-EUA, há um reconhecimento do Brasil como potência e uma ampliação da agenda bilateral. Importante ressaltar que é a proatividade brasileira que favorece a construção do Diálogo Estratégico e não uma ação por parte dos EUA. Há também um descolamento do Brasil das políticas para a América Latina como conjunto, resultado do prestígio que o país alcança ao rechaçar à fórmula de alinhamento automático dos anos 1990. A lógica passa a ser de engajamento e contenção, com os EUA oferecendo concessões à parceria com o Brasil (Pecequilo 2015). Nesse sentido, é um período no qual supera-se a polarização maniqueísta “autonomia versus alinhamento", com o Brasil reconhecendo seu potencial, mas sem descartar o tradicional bom relacionamento com a potência hemisférica.

\section{O BRASIL FRENTE À MUDANÇA DA GRANDE ESTRATÉGIA DOS EUA NA ERA TRUMP}

O anúncio da nova política de armas nucleares, em fevereiro de 2018 , dá fim à Era Obama de busca por minimizar o peso desse tipo de armamento na política de defesa americana. Segundo Trump, o objetivo é dotar os EUA de uma capacidade nuclear inexpugnável, com um arsenal forte o bastante para deter qualquer ato de agressão. O secretário de defesa, Jim Marttis, afirmou que essa mudança reflete a necessidade de "olhar o mundo 
como ele é, e não como nós gostaríamos que fosse" (The Washington Post 2018). Obama havia buscado empreender uma política externa e de segurança de liderança pelo exemplo, sendo alvo de críticas pela administração Trump por ser considerada demasiadamente idealista. Essa nova postura de busca pela primazia nuclear é resultado da leitura de que China e Rússia estão aumentando seu arsenal, e não o diminuindo como Obama esperava. Assim, tal como à época da doutrina de contenção na Guerra Fria, os EUA priorizam as grandes potências e focam sua Grande Estratégia na Eurásia.

Nesse redirecionamento da Grande Estratégia, que parece se decidir pela primazia, o Brasil não tem um papel relevante. A estratégia de concertação pelos EUA seria a que abre mais espaço de manobra para a inserção internacional do Brasil. No entanto, a busca pela primazia limita a atuação brasileira por ser mais agressiva, bem como pela posição geopolítica do país, distante dos teatros preferenciais. A América Latina, nesse contexto, mantém um papel secundário de zona de influência inconteste. A corrente norte-americana de desengajamento, ou isolamento, também cercearia o Brasil e a região no sentido de que reforça a agenda dos ilícitos transnacionais como prioridade no relacionamento hemisférico por serem problemas considerados de segurança interna dos EUA.

É importante reforçar que, independentemente qual seja a Grande Estratégia definida por Washington, é o Brasil que define o seu lugar nela. Os EUA são reativos à atuação brasileira, e historicamente com tendência à homogeneização das políticas para a América Latina. Portanto, quanto mais alinhada a $\mathrm{PEB}$, menos relevante é o Brasil na estratégia do país. Com a chegada de Michel Temer ao poder, o Brasil consolida o processo de abandono da busca por liderança regional e projeção internacional. Contudo, esse fenômeno já pode ser observado desde o recuo da política externa do governo Dilma Rousseff e a grande diminuição na intensidade da agenda sul-americana. Em 2013, há um breve período em que a presidente busca retomar o vigor da $\mathrm{PEB}$ a fim de contrabalançar a crise política interna. Nesse contexto, destacam-se a atuação frente aos casos de espionagem pelo governo dos EUA, bem como a inauguração do Porto de Mariel em Cuba - situações que incitam desconforto na relação bilateral. Não obstante, os efeitos da crise financeira internacional se fazem sentir no Brasil, tal como em outros países emergentes. Encerra-se o período de boom no preço das commodities, cujo impacto sobre a economia incide diretamente sobre os investimentos e os subsídios governamentais às grandes empresas nacionais. Em relação à $\mathrm{PEB}$, as elites nacionais assumiram um discurso de que ela era excessivamente ideologizada, principalmente na América do Sul, rechaçando a cooperação com os países vizinhos mais voltados à esquerda. Dessa forma, rompe-se a aliança de uma política externa 
que tinha a seu favor recursos disponíveis para a projeção do Brasil a partir da atuação de grandes empresas nacionais. A exposição dos escândalos de corrupção na Petrobras a partir de 2014, com grande cobertura midiática, logo difundiram-se às maiores empreiteiras e mineradoras do país, o que acaba por limitar o avanço dos investimentos na integração regional, que tinha como principal estratégia a construção de ambiciosos projetos de infraestrutura.

Com a chegada de Michel Temer ao poder, abandona-se o compromisso estratégico com a política externa. Por razões essencialmente ideológicas, a atual gestão busca aprofundar a cooperação do Brasil com a Aliança do Pacífico, incentivando o papel periférico do país por meio da supressão de barreiras comerciais. Em dezembro de 2016, na $34^{a}$ reunião do Conselho Empresarial Brasil-Estados Unidos (CEBEU), reitera-se uma inserção externa subordinada que abre mão dos ganhos de autonomia auferidos nos últimos anos. Apesar das incertezas quanto às possibilidades de parceria com o governo Donald Trump, a PEB ruma em busca de uma agenda mais ampla de liberalização comercial e de investimentos junto à potência hegemônica (Ramos 2017). Um sinal positivo aos objetivos de alinhamento foi o cumprimento de Trump a Michel Temer (2016-2018) pelas reformas e medidas implementadas "para promover o crescimento do Brasil" (Portal Planalto 2016). O objetivo é assegurar um caminho mais livre em direção ao esvaziamento do Mercosul, a partir da flexibilização das normas do bloco, o que levaria ao fim da união aduaneira. Embora tenha iniciado ainda na presidência de Michel Temer em parceria com Maurício Macri (2015-2019), presidente da Argentina, essa tendência se aprofundou no governo de Jair Bolsonaro. Mais uma vez, o objetivo era ampliar o espaço de manobra para um (bastante controverso) acordo de livre-comércio entre Mercosul e União Europeia, bem como para facilitar acordos bilaterais de liberalização com os Estados Unidos, sem a necessidade de negociações em bloco (Denis 2016).

A influência dos EUA na definição da agenda regional também é aprofundada, tendo em vista os reiterados esforços no combate aos ilícitos transnacionais na América do Sul. Em diversas ocasiões, a diplomacia brasileira tem afirmado a importância central da cooperação regional no monitoramento das fronteiras como principal problema securitário da região. Ainda que certamente seja uma preocupação tradicional da PEB, é interessante perceber como instrumentaliza os objetivos dos EUA na região, assim como desloca a percepção de ameaça na América do Sul. Nesse sentido, a defesa estratégica dos recursos e da integridade territorial da região dá lugar a ações que identificam no crime organizado interno os principais focos de ameaça. O silêncio do Brasil frente à iminência da ins- 
talação de bases americanas na Argentina, sendo uma na tríplice fronteira, bem como a alteração no marco regulatório do pré-sal, são representativos desse processo de subordinação aos interesses hegemônicos (Amaral 2016; Medeiros et al. 2017).

Por conta dos fatores elencados até aqui, o Brasil tem perdido espaço nos fóruns e instituições internacionais, o que deve agravar a perda de relevância na Grande Estratégia dos EUA. As discussões da crise na Venezuela, ocorrendo principalmente no âmbito da OEA em detrimento de espaços mais autônomos como a Unasul, também são indícios desse recuo da $\mathrm{PEB}$. Ou seja, além de a estratégia da primazia ser focada nas potências que empreendem um hard balancing, minimizando a importância dos organismos internacionais, nem mesmo como soft balancing o Brasil tem atuado. Mesmo sendo tradicionalmente um parceiro importante dos EUA na América do Sul, com uma função de estabilizador regional, esse contexto de grande retraimento na PEB acaba por realizar uma autocontenção. Nesse sentido, não há lugar de relevância para o Brasil na Grande Estratégia dos EUA, principalmente porque a dinâmica de engajar para conter não precisa ser feita (Pecequilo 2015). Em outras palavras, ao fim e ao cabo, é o Brasil que define seu lugar na Grande Estratégia dos EUA, e com uma política externa subordinada o país se mantém dentro da lógica homogênea do pensamento americano para a América Latina como região de influência natural e inconteste.

\section{CONSIDERAÇÕES FINAIS}

Esse trabalho procurou avaliar a relação entre a política externa brasileira e a Grande Estratégia dos Estados Unidos. Em termos efetivos, observa-se que, ao longo do tempo, o perfil de relações que o Brasil exerceu com os EUA dependeu muito mais das questões internas do Brasil e como isso refletia em sua inserção internacional, do que propriamente das alterações na Grande Estratégia dos EUA. Isso torna-se mais claro no período pós-Guerra Fria, onde observa-se na literatura e nos documentos variações na Grande Estratégia dos EUA. Afinal, as mudanças do perfil de atuação do Brasil e de sua interação com Washington, ao longo desse período, estiveram muito mais condicionadas pelas alternâncias dos projetos políticos nacionais e pelo contexto global da terceira e quarta fases de ruptura, do que por decorrência das alterações na Grande Estratégia dos EUA.

A conjuntura internacional atravessa uma fase de instabilidade. $\mathrm{O}$ processo de recomposição hegemônica, que se acentuou desde o início do século XXI, traz desafios para a inserção internacional do Brasil. As variações nas respostas que Washington dá a esse contexto internacional 
condicionam a capacidade do Brasil de desenvolver uma estratégia definida. O eventual abandono da tradição liberal no plano internacional, como parecem indicar os últimos documentos estratégicos dos EUA, esvaziam os organismos internacionais, espaços tradicionais da atuação diplomática brasileira.

O contexto de instabilidade mundial é agravado pelo conturbado cenário político interno, que se configura como o principal limitador da inserção internacional brasileira. $\mathrm{O}$ abandono do avanço no processo de integração regional, por meras razões ideológicas, serve como elemento de autocontenção e limita a perspectiva de um relacionamento relevante com os EUA. A esse cenário conjuntural ainda se soma o isolamento geopolítico do Brasil em relação à Eurásia - principal palco geoestratégico da atualidade.

A conjunção dessas transformações no âmbito conjuntural (mudança na Doutrina Nuclear dos Estados Unidos) e estrutural (recomposição hegemônica) impõe ao Brasil uma redefinição de sua inserção internacional. $\mathrm{O}$ acirramento das interações entre as Grandes Potências redimensiona a geopolítica global e amplifica a tendência de erosão do ordenamento internacional. Assim, caso o Brasil não reverta a inação diante dessa conjuntura no plano externo, o ocaso de qualquer pretensão de liderança regional brasileira deve ser efetivado.

\section{REFERÊNCIAS}

Amaral, Roberto. 2016. "Serra e o servilismo na política externa”. Portal Brasil no Mundo. http://brasilnomundo.org.br/analiseseopiniao/serraeoservilismonapoliticaexterna/\#.V8ubYZgrLIV3.

Anderson, Perry. 2015. A Política Externa Norte-Americana e seus Teóricos. São Paulo: Boitempo, 2015.

Atkins, G. Pope. 1989. Latin America in the international political system. Boulder: Westview Press.

Brzezinski, Zbigniew. 1986. Game plan: a geostrategic framework for the conduct of the U.S. Soviet Contest. New York: Atlantic Montlhy Press.

Brzezinski, Zbigniew. 2012. Strategic Vision. New York: Basic Books.

Cervo, Amado Luiz. 2008. Inserção Internacional: formação dos conceitos brasileiros. São Paulo: Saraiva. 
Cervo, Amado Luiz, and Clodoaldo Bueno. 2011. História da Política Exterior do Brasil. Brasília: Editora da UNB.

Cervo, Amado Luiz, and Mario Rapoport. 2015. História do Cone Sul. Rio de Janeiro: Revan.

Denis, Francisco. 2016 "A encruzilhada de um Mercosul sem consenso". Portal Brasil no Mundo. http://brasilnomundo.org.br/noticias/a-encruzilhada-de-um-mercosul-sem-consenso/.

Fiori, José L. 2017. O lugar da Rússia e da guerra na nova estratégia global dos EUA. Federação Única dos Petroleiros (FUP), 2017.

Hobsbawm, Eric. 2010. A Era dos Extremos: o breve século XX. São Paulo: Companhia das Letras, 2010.

Huntington, Samuel. 1997. O Choque das Civilizações e a Recomposição da Nova Ordem Mundial. Rio De Janeiro: Objetiva.

Kissinger, Henry. 1994. Diplomacy. New York: Penguin Press, 1994.

Martins, José Miguel Q. 2008. Digitalização e Guerra Local: como fatores de equilíbrio no Sistema Internacional. Tese de Doutorado em Ciência Política, Universidade Federal do Rio Grande do Sul, Porto Alegre, 2008.

Mearsheimer, John. 1982. Maneuver, "Mobile Defense, and the NATO Central Front". International Security, Cambridge, 1982, v. 6, n. 3, p. 104-122, winter $1981 / 82$.

Medeiros, Josué, Gonzalo Berrón, and Lys Ribeiro. 2017. "Autor de uma política externa desastrosa, Serra sai pela porta dos fundos". Portal Brasil no Mundo. http://brasilnomundo.org.br/analises-e-opiniao/autor-de-uma-politica-externa-desastrosa-serra-sai-pela-porta-dos-fundos/\#.WQoFSdIrKoo.

Mello, Leonel I. A. 1999. Quem tem medo da geopolítica? São Paulo: Edusp/Hucitec.

Moniz Bandeira, Luiz A. 2010. Brasil, Argentina e Estados Unidos: conflito e integração na América do Sul (da Tríplice Aliança ao Mercosul). Rio de Janeiro: Civilização Brasileira.

Montgomery, Evan Braden. 2014. "Contested Primacy in the western Pacific: China's Rise and the Future of U.S. Power Projection". International Security 38, no. 4: $115-149$. 
Pecequilo, Cristina S. 2011. A Política Externa dos Estados Unidos: continuidade ou mudança? - 3. ed. ampl. e atual. Porto Alegre: Ed. da UFRGS.

. 2015. "Do Alinhamento e Autonomia ao Engajamento e Contenção: o repensar das relações bilaterais Brasil-Estados Unidos". Revista Esboços 21, no. 32: $92-114$.

Pinheiro, Letícia. 2000. "Traídos pelo desejo: um ensaio sobre a teoria e prática da política externa brasileira”. Revista Contexto Internacional 22, no. 2: 305-335.

Portal Planalto. 2016. Por telefone, Trump elogia Temer por reformas e medidas para o Brasil voltar a crescer. 13 de dezembro de 2016. http://www2.planalto.gov.br/ acompanhe-planalto/noticias/2016/12/por-telefone-trump-elogia-temer-por-reformas-e-medidas-para-o-brasil-voltar-a-crescer.

Porter, Patrick. 2013. Sharing Power? Prospect for a U.S. Concert-Balance Strategy. Carlisle: U.S. War College Press.

Ramos, Leonardo. 2017. "Brasil e Estados Unidos: livre comércio à vista?" Portal Brasil no Mundo. http://brasilnomundo.org.br/analises-e-opiniao/brasil-e-estados-unidos-livre-comercio-a-vista/\#.WQoEiNIrKoo.

Sennes, Ricardo. 2003. As mudanças da política externa brasileira nos anos 80: uma potência média recém industrializada. Porto Alegre: Ed. da UFRGS.

Smith, Peter. 1996. Talons of the eagle: dynamics of U.S.-Latin American relations. New York: OUP.

Spykman, Nicholas John. 1942. America's strategy in world politics: the United States and the balance of power. New York: Harcourt, Brace and Company.

The Washington Post. 2018. Pentagon unveils new nuclear weapons strategy, ending Obama-era push to reduce U.S. arsenal, by Paul Senne. https://www.washingtonpost. $\mathrm{com} /$ world/national-security/pentagon-unveils-new-nuclear-weapons-strategy-ending-obama-era-push-to-reduce-us-arsenal/2018/02/02/fd72ad34-083911e8-ae28-e370b74ea9a7_story.html?utm_term=.caf7c7d13540.

U.S. Department of State. 2017. National Security Strategy of The United States of America. https://www.whitehouse.gov/wp-content/uploads/2017/12/NSSFinal-12-18-2017-0905.pdf.

1991. National Security Strategy of the United States. Disponível em: http://nssarchive.us/NSSR/1991.pdf. 
2002. National Security Strategy of the United States. Disponível em: https://www.state.gov/documents/organization/63562.pdf.

2010. National Security Strategy of the United States. Disponível em: https://www.state.gov/documents/organization/63562.pdf.

Vizentini, Paulo G. F. 2004. A Política Externa do Regime Militar Brasileiro. Porto Alegre: Ed. da UFRGS. 


\section{NOTAS}

1. Tradução livre dos autores.

2. O desenvolvimento da Grande Estratégia dos Estados Unidos ao longo da história nasceu da conjunção da perspectiva de excepcionalismo e universalismo. Derivada da formação do sentimento nacionalista que se consolida ao longo do processo de independência, a visão que se solidifica dentro do establishment estadunidense é a de que, ao mesmo passo que Washington possui características únicas que o colocam como uma espécie de farol para o mundo - o que levou o país a adotar uma postura isolacionista em alguns momentos da sua história -, os EUA teriam um dever messiânico de expandir seus valores para o resto da humanidade (Kissinger 1994; Anderson 2015).

3. A Ásia passa a assumir posição prioritária para os EUA. Apesar do governo de Jimmy Carter (1977-1981) ter revisto, em grande medida, políticas de Nixon, este manteve a prioridade geoestratégica centrada na massa euroasiática.

4. Os EUA passaram a buscar a primazia e a desestruturação do equilíbrio nuclear que preponderou durante a Guerra Fria. Ou seja, o objetivo passou a ser acabar com a capacidade de segundo ataque de Moscou. O governo de Ronald Reagan (1981-1989), nesse sentido, procurou desenvolver capacidades estratégicas, como é o caso da Strategic Defense Initiative (SDI), para dar base material para essa nova Grande Estratégia voltada à unipolaridade. Adotada no governo, a SDI tinha como objetivo central desenvolver capacidades defensivas anti-balísticas. Embora o programa tenha sido abandonado posteriormente, foi um primeiro indicativo dessa nova perspectiva.

5. Como exemplo dessas medidas, buscava-se a liberalização do mercado de informática, a redução do protecionismo, a ampliação de privilégios a empresas estrangeiras, a privatização de estatais e a negociação da dívida através do FMI.

6. O Offshore balance trata-se de estratégia voltada à contenção do inimigo através do apoio na rede de aliados, permitindo algum espaço de recuo por parte das demais potências em caso de confronto. Assim, utiliza-se de uma doutrina voltada ao atrito, ao desgaste do inimigo e não sua aniquilação.

7. A JOAC baseia-se na ideia de emprego de domínio cruzado de tecnologias militares avançadas múltiplas, como a tecnologia stealth, armas de energia direta, mísseis hipersônicos. Nesse contexto, o conceito que foi incorporado pelo Departamento de Defesa e transformado em "Joint Concept for Access and Maneuver in the Global Commons (JAM-GC)” ganhou variações e ampliou o papel do exército. Cabe des- 
tacar que esse conceito diz respeito a uma estratégia mais agressiva frente às demais potências e de caráter mais unilateral. Portanto, reforça um caráter unipolar.

8. A chegada de Barack Obama ao poder nos EUA parecia indicar uma retomada da busca pela concertação hegemônica assentada no liberalismo institucional. Segundo Porter (2013), a estratégia da concertação estaria voltada para uma ação de compartilhamento de poder. Em que pese o governo de Obama ter adotado esse perfil liberal-internacionalista, isto é, ter dado mais valor para o peso da legitimidade internacional, isso não representou uma alteração na tendência à busca pela primazia.

9. A menção ao Brasil ocorre seis vezes ao longo do documento, sendo que cinco delas ocorrem nas conclusões do documento, no item que cita os "centros de influência emergentes". A outra citação ocorre no início do documento na seção "Renewing American Leadership - Building at Home, Shaping Abroad”. 
O BRASIL E A GRANDE ESTRATÉGIA DOS EUA:

ASPECTOS HISTÓRICOS CONJUNTURAIS

\section{RESUMO}

Esta pesquisa tem como objetivo analisar os efeitos que as alterações na Grande Estratégia dos Estados Unidos geram para a inserção internacional do Brasil. Procura vincular as oscilações nas relações Brasil-EUA e as variações no contexto geopolítico sul-americano, vinculando a conjuntura histórica com a atualidade.

Palavras-chave: Estados Unidos; Brasil; Grande Estratégia.

\section{ABSTRACT}

This research aims to analyze the effects that the changes in the Great Strategy of the United States generate for the international insertion of Brazil. It seeks to link the oscillations in Brazil-US relations and the variations in the South American geopolitical context, linking the historical conjuncture with the present.

Keywords: United States; Brazil; Great Strategy. 